\author{
Military Technical College \\ Kobry El-Kobbah, \\ Cairo, Egypt.
}

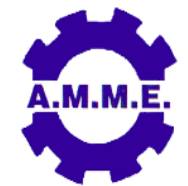

\title{
SOLID ROCKET MOTORS INTERNAL BALLISTIC MODEL WITH EROSIVE AND CONDENSED PHASE CONSIDERATIONS
}

\author{
F. Mingireanu ${ }^{1}$, N. Jula ${ }^{2}$, S. Miclos ${ }^{3}$, L. Baschir ${ }^{3}$ and D. Savastru ${ }^{3}$
}

\begin{abstract}
Solid rocket motors are used for propulsion units of both suborbital and orbital aerospace vehicles. Their main advantages are their simplicity, low cost and reliability. Due to attainable high thrust they have a wide application as boosters (as space shuttle boosters, Delta rocket boosters). They were also used as main stages, retrorocket units, stage separation control units, main propulsion units for suborbital vehicles. An interior ballistics model is implemented and applied for a double base and composite propellant boosters to be used for a boosted dart suborbital vehicle. Erosion and condensed phase are taken into account and numerical results are shown in comparison with experimental data obtained on test firings for each motor. The advantages of the implementation are that it offers a fast calculation of the main parameters of the solid rocket motor unit (thrust, burn time, specific impulse, total impulse). The solid fuel characteristics and the geometry of the motor are contained within two input files while the results of the calculations are presented to the user in a several output files. The motors are built using steel as a casing material and test firings are performed on a horizontal test bench.
\end{abstract}

\section{KEY WORDS}

ballistic model, solid, rocket, motor, model

Romanian Space Agency, Str. Mendeleev; Nr. 21-25; Bucharest; 010362; Romania.

Military Technical Academy, 39-49 George Cosbuc Avenue, Bucharest, RO 040531, Romania.

3 National Institute of R\&D for Optoelectronics INOE 2000, Atomistilor Street, Magurele, Ilfov county, 077125, Romania. 


\section{NOMENCLATURE}

$\begin{array}{ll}A_{a} & \text { total burning surface, } \mathrm{m}^{2} \\ \rho_{P} & \text { propellant density, } \mathrm{kg} \cdot \mathrm{m}^{-3} \\ U_{a} & \text { burn rate, } \mathrm{m} \cdot \mathrm{s}^{-1} \\ C, n & \text { burn rate coefficients } \\ A, B & \text { burn rate temperature dependence coefficients } \\ F(u) & \text { burn rate erosion function } \\ u & \text { flow velocity of combustion products inside the SRM casing } \\ p & \text { combustion pressure } \\ T_{i} & \text { initial solid propellant temperature } \\ \rho_{0} & \text { density of the combustion products in the combustion chamber } \\ \rho_{c} & \text { density of the combustion products in the throat section } \\ a_{0} & \text { sound velocity in the combustion chamber } \\ a_{c} & \text { sound velocity in the throat section } \\ T_{0} & \text { temperature of the combustion products in the chamber } \\ T_{c} & \text { temperature of combustion products in the throat section } \\ k & \text { ratio of specific heats for the combustion products } \\ A_{c} & \text { nozzle throat section } \\ K_{a} & \text { ratio between burning surface and nozzle throat section } \\ C_{p} & \text { constant pressure specific heat } \\ C_{V} & \text { constant volume specific heat } \\ A_{c} & \text { nozzle critical section }\end{array}$

\section{INTRODUCTION}

Solid rocket motors (SRM) have a wide application as propulsion units for various aerospace vehicles either for suborbital or for orbital flight [1-4]. SRMs are widely used due to their simplicity, reliability and low cost of operation. At the same time, an SRM needs less ground infrastructure, hence, allowing the overall vehicle to be simpler than a liquid propelled one [5]. A well-known example is represented by the space shuttle solid rocket boosters (SRB) shown in Fig. 1. Suborbital sounding rockets also use SRMs as their main propulsion unit. Such an example is the MAXUS sounding rocket (Fig. 2) operated by the European Space Agency (ESA) from ESRANGE/Sweden. 
In order to correctly design a SRM unit for a specific mission one needs to size the unit for a specific thrust curve given a certain propellant. Throughout the design procedure an interior ballistic code is useful and it is applied towards obtaining a preliminary design which is then tested on a firing bench and refined through multiple firing tests and re-runs of the simulations. Our research group has developed an inhouse interior ballistics code that allows for preliminary designs of various SRM units. The code allows the user to input various geometries of the fuel grain, various types of solid fuel as well as various combustion chamber/nozzle dimensions [8].

Typically the SRM uses one of the two types of propellants:

- Homogenous (e.g.: double base propellants)

- Heterogeneous (e.g.: composite propellants).

\section{INTERIOR BALLISTICS MODEL}

The entire code is written in FORTRAN 95 and the output is shown using GNUPLOT package through various options displayed when the simulation ends. The raw data is also provided to the user in several output files. Typical run for an SRM simulation is between several seconds to several minutes; the run time depends on the dimensions of the SRM unit, the burn time as well as fuel grain geometry. The burn rate of the solid propellant is the core of the SRM model [5, 9-13].

Based on the burn rate the amount of solid propellant burnt can be determined by the following equation:

$G_{a}=A_{a} U_{a} \rho_{p}$

A simplified burn rate relation assumes dependence only on the combustion pressure:

$U_{a}=c p^{n}$

Yet a more complex burn rate equation takes also in the account the velocity vector of the combustion gases that "wash" the surface of the solid propellant [14-20]:

$U_{a}=f_{1}\left(T_{i}\right) f_{2}(p, u)$

where

$$
\begin{aligned}
& f_{1}\left(T_{i}\right)=\frac{A}{B-T_{i}} \\
& f_{2}(p, u)=a\left(\frac{p}{70}\right)^{n}(1+\xi \rho u)
\end{aligned}
$$

The extra-term $\xi \rho u$ contains the erosion component; it basically describes how much the burn rate is increased due to the flow of the combustion gases over the solid propellant surface. For a new solid propellant formulation the parameters $c$ and $n$ 
from the burn rate equation are to be determined experimentally either in a calorimetric bomb or in a Ballistic Evaluation Motor (BEM).

Next the mass flow rate per cross area of the solid rocket motor from the combustion chamber is determined by the following equation:

$$
\dot{m}=\rho_{0} a_{0} A_{c}\left(\frac{\rho_{c}}{\rho_{0}}\right)\left(\frac{a_{c}}{a_{0}}\right)
$$

Considering the flow to be isentropic then we can write a relation between the density of the combustion gases in the critical section and the combustion chamber:

$$
\frac{\rho_{c}}{\rho_{0}}=\left(\frac{T_{c}}{T_{0}}\right)^{\frac{1}{k-1}}=\left(\frac{2}{k+1}\right)^{\frac{1}{k-1}}
$$

Assuming that the combustion gases are modeled by the perfect gas equation then one obtains the mass flow through the nozzle as follows:

$$
\dot{m}=\rho_{0} a_{0}\left(\frac{2}{k+1}\right)^{\frac{k+1}{2(k-1)}} A_{c}
$$

Equation (7) can be re-written as it follows:

$$
\dot{m}=\Gamma \frac{p_{0} A_{c}}{\sqrt{g R T_{0}}}
$$

by using the notation

$$
\Gamma=\sqrt{k}\left(\frac{2}{k+1}\right)^{\frac{k+1}{2(k-1)}}
$$

In order to determine the pressure in the combustion chamber it is used a "continuity" equation:

$$
\rho_{p} A_{a} U_{a}=\Gamma \frac{p_{0} A_{s}}{\sqrt{g R T_{0}}}+\frac{d}{d t}\left(\rho_{0} V_{0}\right)
$$

The density of the solid propellant is a parameter that is defined by the user in the input file containing solid fuel characteristics. It can either be estimated theoretically based on the formulation of the solid propellant to be used or experimentally by using a solid propellant sample. Substituting the burn rate equation (2), equation (10) becomes:

$$
\rho_{p} A_{a} c p_{o}^{n}=\Gamma \frac{p_{0} A_{s}}{\sqrt{g R T_{0}}}+\rho_{0} \frac{d V_{0}}{d t}+V_{0} \frac{d \rho_{0}}{d t}
$$


Through simple mathematical transformations equation (11) can be transformed to become:

$$
\left(\rho_{p}-\rho_{0}\right) g R T_{0} A_{a} c p_{0}^{n}=\Gamma p_{0} A_{c} \sqrt{g R T_{0}}+V_{0} \frac{d p_{0}}{d t}
$$

Next it is assumed that the density of the combustion gases is negligible in respect to the density of the solid propellant and, hence, equation (12) transforms into:

$$
\rho_{p} g R T_{0} A_{a} c p_{0}^{n}-\Gamma p_{0} A_{c} \sqrt{g R T_{0}}=V_{0} \frac{d p_{0}}{d t}
$$

By assuming constant pressure operation it is possible to obtain a more simplified equation for the pressure of the combustion gases:

$$
p_{0}=\left(\rho_{p} c V K_{a}\right)^{\frac{1}{1-n}}
$$

The ratio between the burning surface and the throat section of the nozzle is an important design parameter for a new SRM unit. At the same time, it can be observed basing on equation (14) that the value of the index $n$ is important for the stability of the combustion process of a solid propellant. If $n>1$ then the derivative of the pressure given by equation (14) is positive and, hence, the combustion process is unstable; in other words, any change in pressure would lead to a further increase in pressure which would lead to structural failure of the SRM casing once the maximum pressure is exceeded. On the other hand, if $n<1$ then upon a slight increase of pressure the derivative of the pressure is negative and the pressure is "forced" back to nominal values. Hence, the combustion process is stable.

As opposed to equation (14) which considers constant pressure operation and is useful to estimate overall parameters of an SRM (before an actual simulation is performed), equation (13) can be used in order to simulate the operation of an SRM (including transient ignition and shutdown phases).

In case of condensed phase the main assumption is that the flow consists of combustion gases and condensed products that do not interact chemically with each other [21-27].

Hence, the ratio of specific heat of the gas mixture used for calculations in the combustion chamber is given by:

$k_{\text {mix }}=\frac{C_{\text {pmix }}}{C_{\text {pmix }}-R}$

The ratio of specific heat for the two-phase flow used for calculations in the nozzle of the solid rocket motor is given by: 


$$
k_{2 \text { phase }}=k_{\text {gas }} \frac{1+\phi \frac{C_{s}}{C_{p g a s}}}{1+\phi k_{\text {gas }} \frac{C_{s}}{C_{p g a s}}}
$$

For a mixture of $n$ species of gases the specific heat at constant pressure is given by:

$$
C_{p g a s}=\frac{1}{n} \sum n_{i} C_{p i}
$$

For a mixture of $n$ species of gases and $n$ species of solid condensed phase particles the specific heat at constant pressure is given by:

$$
C_{p \operatorname{mix}}=\frac{1}{n} \sum\left(n_{i} C_{p i}+n_{s} C_{p s}\right)
$$

For a two-phase flow the molecular weight takes into account the presence of condensed phase by diving the total mass of the system by the moles of gas in the system.

The derivation of equations (15) through (18) assumes a frozen flow condition. Hence, while assuming no thermal or velocity particle lag the derivations are based on momentum and energy equations written for steady isentropic flow. In reality the condensed phase particles have a velocity particle lag and a certain heat flow is associated with the thermal interaction between the solid particles and the mixture of gas species. For a more accurate two-phase flow model these interactions have to be taken into account. However, based on experimental determinations these interactions are of secondary importance and the corrections provided by the equations (15) through (18) are sufficient for a preliminary design of an SRM while taking into account the two-phase flow characteristics.

In a high performance solid rocket motor the condensed phase particles are not desired since they lower the overall performance of the motor. The performance lowering is due to the fact that the condensed phase particles do not perform work since they do not expand through the nozzle as the gas species. At the same time, the condensed phase particles lower the characteristic velocity due to their higher effective molecular weight.

The integration in time of equation (13) produces the time dependence of the combustion pressure. Within the SRM simulation code a RK-4 [28-29] integration scheme is used. RK-4 offers both stability and reasonable simulation times for accurate numerical solutions.

The main steps of the SRM simulation code are:

- Read geometrical dimensions of the SRM from INPUT.DAT

- $\quad$ Read fuel geometry from FUEL_GEOMETRY.DAT

- Compute initial burning surface (the code can handle end burn and tubular geometry but has additional modules that can be used for other geometries)

Next it follows a repetitive loop until the end-burning condition is met (pressure in the SRM casing lower than a threshold value): 
- Compute initial burn rate based on initial pressure

- Integrate pressure equation (13) using RK-4 module

- Write output data in the OUTPUT.DAT file

The burn rate in the above steps can be either given by equation (2) or (3). The choice can be specified by a user in the INPUT.DAT file.

Upon end of simulation the code calls a routine that uses GNUPLOT application in order to graphically display main output parameters (thrust curve, pressure-curve) based on the option chosen by the user.

\section{SRM TEST BENCH MODEL}

In order to validate the SRM code two SRM units were used. One SRM unit uses composite propellant of low $I_{s p}$ (specific impulse), of $\sim 140$ seconds, while the second SRM unit uses double base propellant with $I_{s p} \sim 200$ seconds.

Both SRM units are developed as propulsion units for a suborbital dart sounding vehicle developed by Electromecanica Ploiesti and ROMSPACE with additional sensors being provided by INOE 2000.

The casings of the SRMs is made of steel (high strength alloyed steel) with the nozzles being made of low-carbon steel in order to prevent burning of the nozzles in the throat section. Coupling of the end-cap and nozzle is performed by using fillets; a high-temp silicone coating is applied in order to prevent gas leakage.

The composite propellant SRM uses one nozzle configuration while the double base propellant SRM uses multiple nozzles configuration in order to optimize the mass of the nozzle block. The composite fuel SRM contains 10 identical segments of fuel grains as shown in Fig. 5.

The composite fuel grains are stack in the motor and the ignition is performed from the end-cap (opposite from the nozzle end). The ignition is performed electrically and provides a safe while short transient time ignition process. The exhaust gases of the composite propellant contain condensed phase and, hence, the exhaust is not smokeless.

The double base SRM contains two identical double base fuel grains as shown in Fig. 6. The igniter for the double bas SRM is shown in between the two fuel grains and is installed in between the fuel grains providing a short ignition time. Each fuel grain has a mass of $7 \mathrm{~kg}$ and at nominal operating pressure (90 bars) burns in 1.71 seconds.

Due to the nature of double base propellants the exhaust gases are smokeless with almost no residue left over in the casing of the SRM.

\section{NUMERICAL RESULTS COMPARED TO EXPERIMENTAL RESULTS}

The main performance characteristic of an SRM is the thrust curve. This shows how the thrust generate by the SRM varies with time. Based on the thrust curve it is 
possible to decide which elements of the SRM have to be changed in order to obtain a thrust curve closer to the operational requirements.

On the test bench the thrust curve is measured by using a load cell which generates a signal proportional with the thrust. The signal is amplified, filtered and digitized. The digital output is then recorded on a PC for later analysis.

Figure 7 shows the composite solid fuel SRM during test firings. The side walls are built to withstand the shock of an accidental explosion of the test SRM.

As can be observed in Fig. 7 the exhaust plume consists of significant amount of condensed phase (while-smoke plume).

Figure 8 shows the double base solid fuel SRM during test firings. It can be noted that the exhaust plume is cleaner with no condensed phase being present. Residual condense phase exists due to secondary components present in double base propellant (ethyl centralite, vaseline etc.). However the percentage of these secondary components is very small when compared to the main components of double base propellant (nitroglycerine, nitrocellulose) and, hence, their associated condensed phase products are negligible.

The comparison between the simulated and experimental thrust curve of composite SRM is shown in Fig. 9.

The erosion process in the case of composite solid fuel SRM is important due to rather large length/diameter ratio and small combustion port (at least during the initial phase of combustion) compared to nozzle throat section. One can observe that by taking into account erosion the simulated thrust curve resembles very close the experimental determined thrust curve.

The simulated specific impulse of the composite fuel SRM is 140 seconds while the measured one is 137 seconds. The comparison between the simulated and experimental thrust curve of double base SRM is shown in Fig. 10.

The erosion effect in the case of the given double base SRM unit is not important because, even from the beginning of the combustion, the combustion port was designed to be significantly larger than the nozzle throat section in order to prevent erosion. Hence, in this case the simulation was performed with the simple burn rate relation (2) rather than the erosive one (3).

The simulated specific impulse of the double base SRM is 204 seconds while the measured specific impulse is 200 seconds. It can be observed that the simulation provides good agreement with the measured thrust curve and measured specific impulse. These two parameters are important when designing a propulsion unit for a given aerospace vehicle.

\section{CONCLUSIONS}

An interior ballistics model has been developed in order to simulate SRMs propulsion units. The model contains both non-erosive and erosive burn rate models depending on the user choice. 
The model also takes into account the condensed phase flow which is significant for the composite propellants through a reformulation of the main thermochemical equations in order to take into account the condensed phase.

Two SRM units has been developed. One SRM unit uses composite propellant and by the choice of geometrical dimensions exhibits significant erosion. The second SRM unit uses double base propellant and by the choice of geometrical dimensions does not exhibit significant erosion.

A good agreement is shown between the simulated thrust curves and the measures thrust curves of both the composite and double base propellant SRMs. The same holds for the simulated specific impulse which is in good agreement with the experimental determined one for both of the SRM units.

Further work is considered especially in the direction of implementing a 1-D model that can capture the variation of pressure throughout the SRM casing. This model allows a more accurate erosion estimation which can be further coupled with the current condensed phase module.

The developed SRM units are intended to be used on low cost reusable suborbital boosted dart vehicles.

\section{ACKNOWLEDGMENTS}

The authors would like to acknowledge the Romanian Space Agency (ROSA) for the continuous support offered throughout this research.

Authors also thank to SC Electromecanica Ploiesti SA and SC TOHAN SA for support during test firings of the SRM units.

They are also grateful for the support received from Spacefleet Ltd which funded the development of the composite propellant SRM.

\section{REFERENCES}

[1] "NASA Sounding Rockets User Handbook Sounding Rockets Program Office", NASA Goddard Space Flight Center, https://sites.wff.nasa.gov/code810/files/SRHB.pdf [July 2015].

[2] Bollerman, B. et al., "Design, development and flight test of Super Loki dart meteorological rocket systems", National, Technical Information Service, U.S. Department of Commerce, AD-750 796, 30 May 1972.

[3] Frunzulica, F., Stoia-Djeska, M., and Mingireanu, F., "Validation with Numerical Simulations of a Simplified Model of a Hybrid Rocket Motor", PAMM, Vol. 15, No. 1, 2015, pp. 429-430.

[4] Mingireanu, F., and Stoia-Djeska, M., "Methane Based Cryogenic Hybrid Rocket Motor Oxidizer Doping", 62rd International Astronautical Congress, IAC11 - D9.2.8, Vol. 10, Cape Town, South Africa, IAF, 2011, pp. 8373-8382. 
[5] Kurov, V. D., and Dolzhanskiy, Yu. M., "Fundamentals of design for solidpropellant rocket missiles", Gosudarstvennoye Nauchno-Tekhnicheskoye Izdatel'stvo Oborongiz, Moskva, 1961.

[6] "Final Set of Space Shuttle Boosters Arrive at NASA - Redorbit", Red Orbit website,

http://www.redorbit.com/news/space/1872295/final set of space shuttle boost ers arrive at nasa/ [May 2010].

[7] "MAXUS sounding rocket", image from Human Spaceflight, Microgravity and Exploration $\quad$ ESA website, http://www.spaceflight.esa.int/impress/text/education/Images/Glossary/Glossary Image35.jpg [May 2010].

[8] Mingireanu, F., and Jula, N., "Workshop on boosted dart optimization", $17^{\text {th }}$ International Conference on Aerospace Sciences \& Aviation Technology, ASAT - 17, Cairo, Egipt, 2017.

[9] Smith, M. L., and Stinson, K. W., "Fuels and combustion", McGraw-Hill, New York, 1952.

[10] Van Mylen, G. J., and Sonntas, R. E., "Fundamentals of classical thermodynamics", $2^{\text {nd }}$ ed., John Wiley and Sons, New York, 1978.

[11] Novozhilov, B. V., "Theory of Nonsteady Burning and Combustion Stability of Solid Propellants by the Zeldovich-Novozhilov Method", Nonsteady Burning and Combustion Stability of Solid Propellants, edited by M. Summerfield, E. W. Price and L. De Luca, Progress in Astronautics and Aeronautics, AIAA, Washington, DC, Vol. 143, chap. 15, 1992, pp. 601-641.

[12] Meynet, N., "Simulation numerique de la combustion d'un propergol solide", Ph.D. Dissertation, Universite Paris VI, Paris, 2005.

[13] Fabignon, Y., Dupays, J., Avalon, G., Vuillot, F., Lupoglazoff, N., et al., "Instabilities and Pressure Oscillations in Solid Rocket Motors", Aerosp. Sci. Technol, Vol. 7, No. 3, 2003, pp. 191-200.

[14] Javed, A., Chakraborty, D., "Universal erosive burning model performance for solid rocket motor internal ballistics", Aerosp. Sci. Technol, Vol. 45, 2015, pp. 150-153.

[15] Sridharan, P., Lal, C. J., Krishnaraj, K., Krishnamoorthy, P. A., "Erosive burning behaviour in a solid rocket motor with composite propellant", 46th AIAA/ASME/SAE/ASEE Joint Propulsion Conference \& Exhibit, AIAA 20106912, Nashville, TN, 2010.

[16] King, M. K., "A model of erosive burning of composite solid propellants", J. Spacecr. Rockets, Vol. 15, No. 3, 1978, pp. 139-146.

[17] Mukunda, H. S., Paul, P. J., "Universal behaviour in erosive burning of solid propellants", Combust. Flame, Vol. 109, No. 1-2, 1997, pp. 224-236.

[18] Kamath, H., Arora, R., Kuo, K. K., "Erosive burning measurements and predictions for a highly aluminised composite solid propellant", 18th Joint Propulsion Conference, Cleveland, OH, U.S.A., 1982, AIAA-82-1111.

[19] Jojic, B., Blagojevic, D. J., "Theoretical Prediction of Erosive Burning Characteristics of Solid Propellant Based on Burning rate Dependence of pressure and initial Temperature and its energy characteristics", 12th Propulsion Conference, Palo Alto, CA, U.S.A., 1976, AlAA-76-697.

[20] Razdan, M. K., Kuo, K. K., "Erosive burning study of composite solid propellant by turbulent boundary layer approach", AIAA Journal, Vol. 17, No. 11, 1979, pp. 1225-1233.

[21] Gilbert M., Allport J., Dunlap R., "Dynamics of two-phase flow in rocket nozzles", ARS Journal, Vol. 32, No. 12, 1962, pp. 1929-1930. 
[22] Farley, J.M., Campbell, C.E., "Performance of Several Method-ofCharacteristics Exhaust Nozzles", NASA-TN-D-293.

[23] Kliegel, J.R. and Nickerson, G.R., "Flow of gas-particle mixtures in axially symmetric nozzles", Detonation and two phase flow, Academic Press, New York, 1962.

[24] Hijlkema, J., Prevost, M., Casalis, G., "On the Importance of Reduced Scale Ariane 5 P230 Solid Rocket Motor Models in the Comprehension and Prevention of Thrust Oscillations", CEAS Space J., Vol. 1, No. 4, 2011, pp. 99107.

[25] Hijlkema, J., Prevot, "Numerically-Assisted Particle Size Distribution Measurements in Reduce-Scale Solid Rocket Motors", J. Propul. Power, Vol. 31, No. 2, 2015, pp. 714-724.

[26] Gallier, S., Godfroy, F., "Aluminum Combustion Driven Instabilities in Solid Rocket Motors", J. Propul. Power, Vol. 25, No. 2, 2009, pp. 509-521.

[27] Lamet, J. M., Fabignon, Y., Tesse, L., Dupays, J., Radenac, E., "Modeling of Propellant Combustion with Nano-Sized Aluminum Particles", 5th European Conference for Aero Space Sciences (EUCASS 2013), Munich, Germany, 2013.

[28] Press, W. H., Teukolsky, S. A., Vetterling, W. T., Flannery, B. P., and Metcalf, M., Numerical Recipes in Fortran 90: The Art of Parallel Scientific Computing, $2^{\text {nd }}$ ed., Cambridge University Press, Cambridge, U.K., 1996.

[29] SLATEC 3.0, General Mathematical Library, Incorporated at Oak Ridge National Laboratory, USA, 1986. 


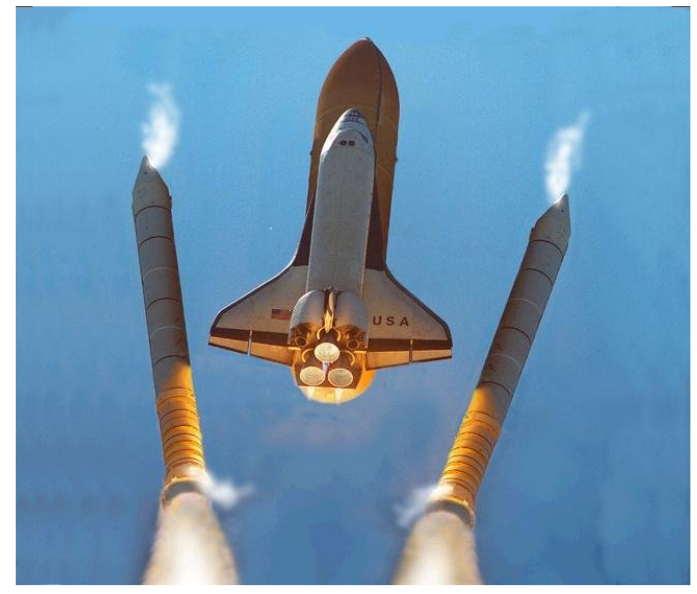

Fig. 1. Space shuttle boosters [6].

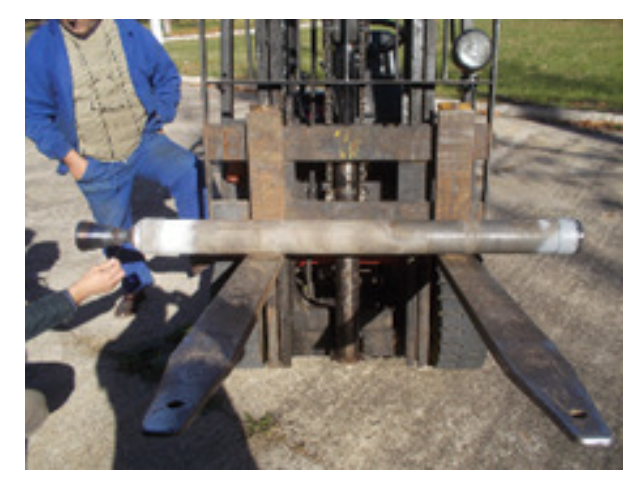

Fig. 3. Composite propellant SRM.

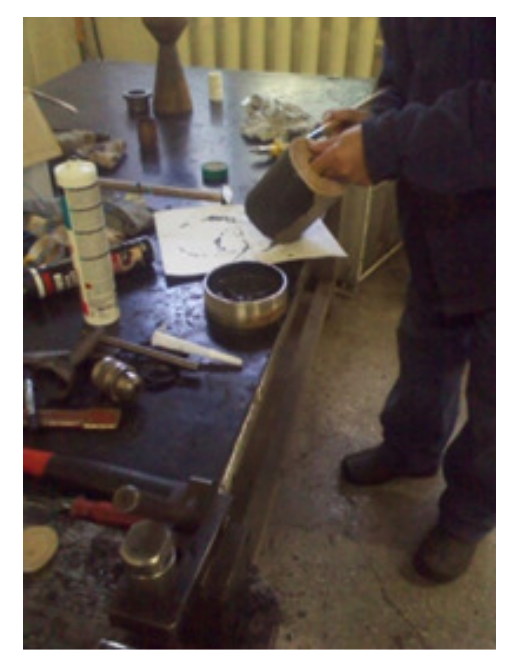

Fig. 5. Composite fuel grains.

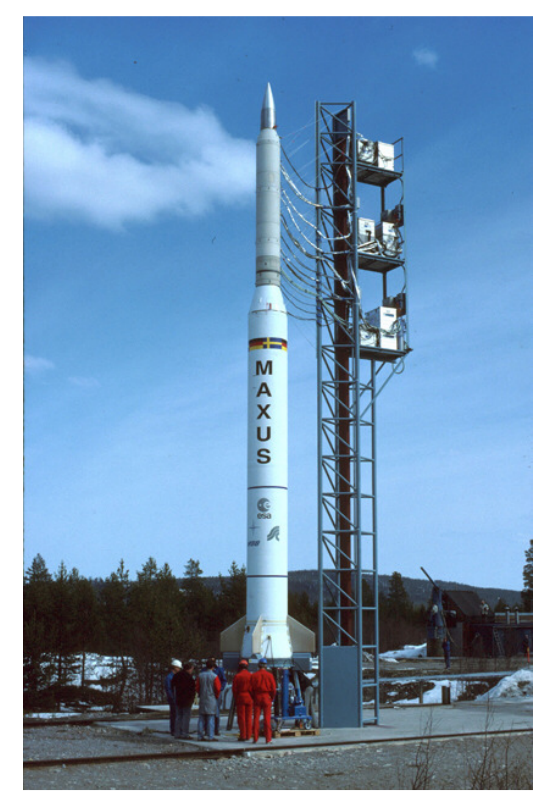

Fig. 2. MAXUS sounding rocket [7].

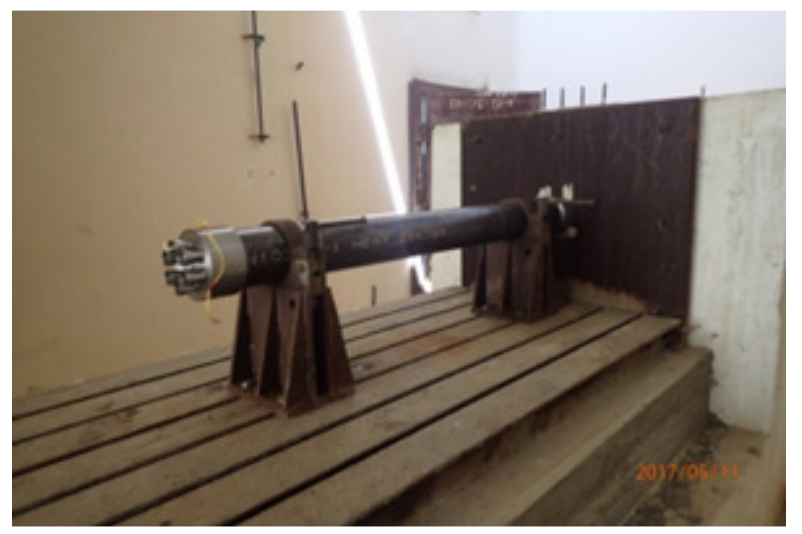

Fig. 4. Double base propellant SRM.

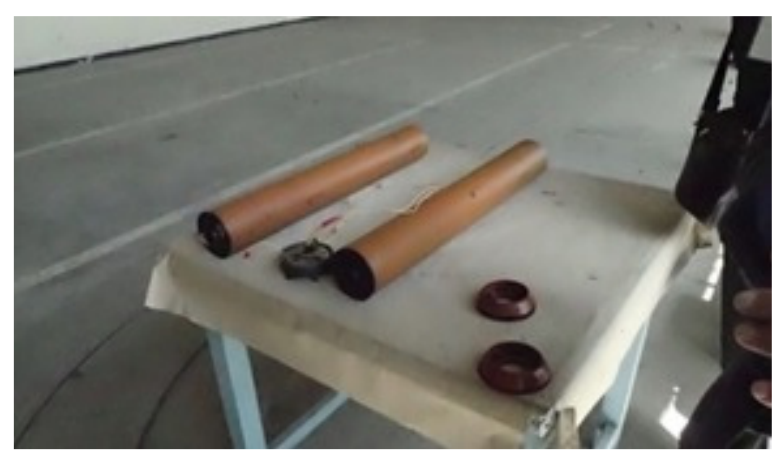

Fig. 6. Double base propellant fuel grains. 


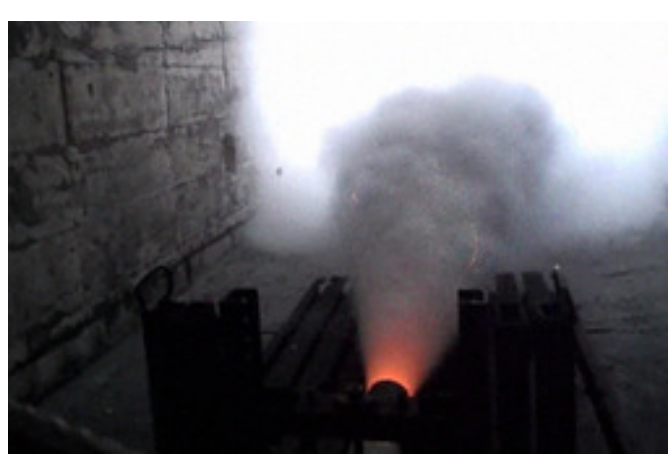

Fig. 7. Composite SRM during firing test.

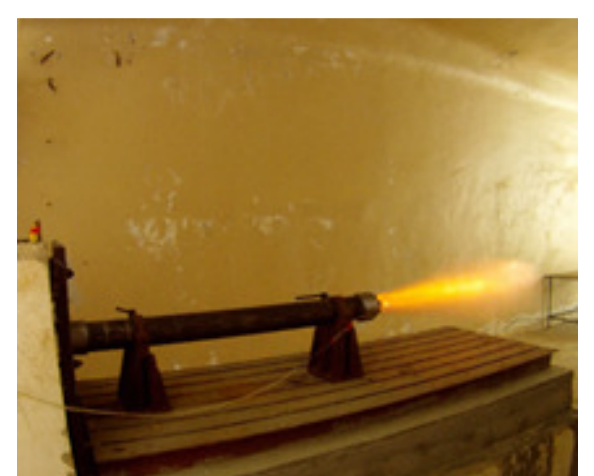

Fig. 8. Double base SRM during test firing.

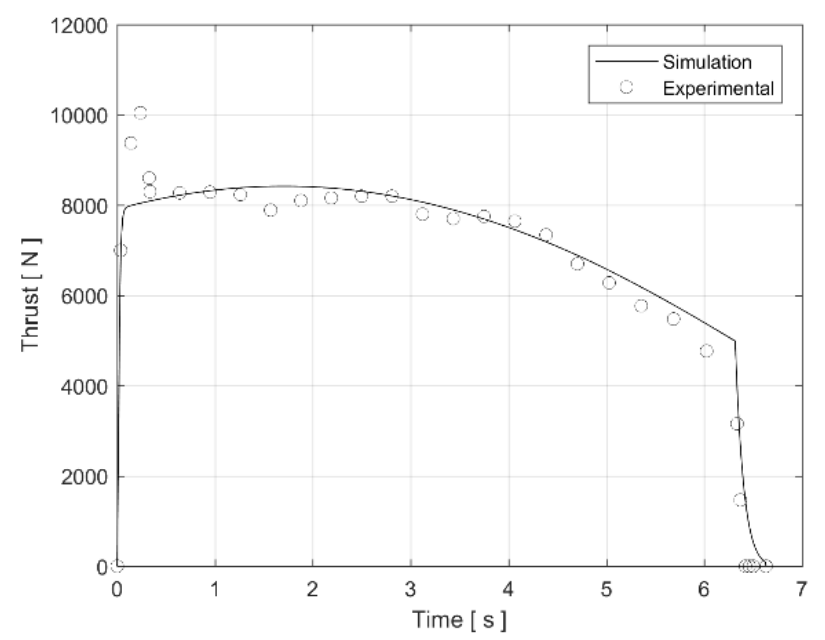

Fig. 9. Composite fuel SRM thrust curve.

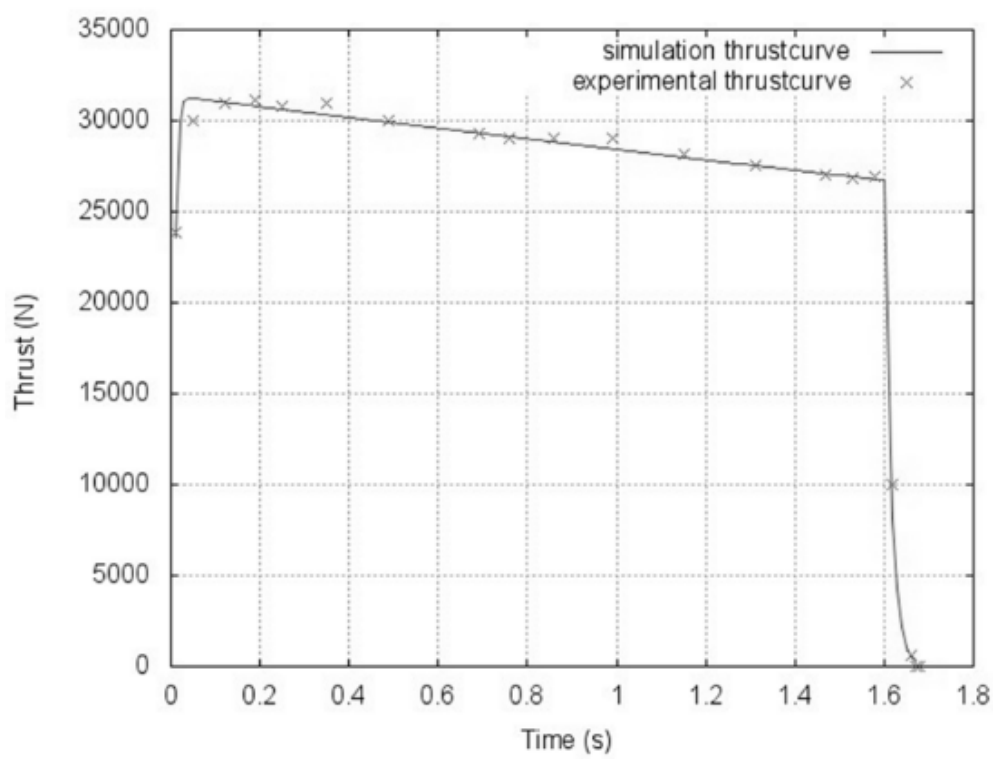

Fig. 10. Double base SRM thrust curve. 